\title{
El feminicidio y la violencia de género en la prensa argentina: un análisis de voces, relatos $y$ actores ${ }^{1}$
}

\author{
Rocio Angélico ${ }^{2}$ \\ Universidad de Buenos Aires, Buenos Aires, Argentina ${ }^{3}$ \\ rocio.angelico@gmail.com \\ Violeta Dikenstein ${ }^{4}$ \\ Universidad de Buenos Aires, Buenos Aires, Argentina ${ }^{5}$ \\ violetadik@hotmail.com \\ Sabrina Fischberg ${ }^{6}$ \\ Universidad de Buenos Aires, Buenos Aires, Argentina ${ }^{7}$ \\ sabri_fischberg@hotmail.com \\ Florencia Maffeo ${ }^{8}$ \\ Universidad Nacional de San Martín, Gral. San Martín, Argentina ${ }^{9}$ \\ florencia_mf@yahoo.com.ar \\ Recibido: 22 de septiembre de 2013 \\ Aceptado: 20 de enero de 2014

\footnotetext{
El presente trabajo es un artículo de investigación científica y tecnológica. En él se exponen los resultados de un trabajo realizado sobre la prensa argentina. El trabajo se inició en el marco del Programa "Poscolonialidad, Pensamiento fronterizo y transfronterizo en los Estudios Feministas" (IDAES- UNSAM) dirigido por la Dra. Karina Bidaseca. No obtuvimos financiamiento para la realización de esta investigación. Las primeras reflexiones sobre este trabajo se presentaron en el Primer Congreso de Estudios Poscoloniales y II Jornadas de Feminismo Poscolonial. Cruzando puentes: Legados, genealogías y memorias poscoloniales, los días 5, 6 y 7 de Diciembre de 2012 realizado en la Biblioteca Nacional en Buenos Aires. Maestria en Derechos Humanos y Politicas Sociales.
} \\ 2 Licenciada en Sociología (UBA) y profesora en Sociología (UBA). \\ 3 Docente de nivel secundario y adultos. Orientadora Social en escuela media. \\ 4 Licenciada en Sociología (UBA). \\ 5 Licenciada en Sociología (UBA). \\ 6 Licenciada en Sociología. \\ 7 Estudiante del Profesorado de Sociologia. \\ 8 Licenciada en Sociología. \\ 9 Personal de Administración y Servicio en la Escuela de Política y Gobierno. Estudiante de la \\ Documento accesible en línea desde la siguiente dirección: http://revistas.javeriana.edu.co
}




\title{
El feminicidio y la violencia de género en la prensa argentina: un análisis de voces, relatos y actores
}

\section{Resumen}

En el presente trabajo nos proponemos abordar un análisis acerca de la publicación de casos de violencia de género y feminicidio, por medio de un relevamiento de cuatro periódicos argentinos durante el primer semestre de 2012. Nos interesa indagar cuáles son los interlocutores privilegiados por los medios a la hora de informar sobre el fenómeno, con el fin de poder distinguir el espacio de enunciación que la prensa otorga a diversos actores. Por medio del análisis de los relatos de los agresores, los familiares, la justicia y las víctimas, nos proponemos observar las diversas posturas y las argumentaciones que se ponen en juego y dilucidar quiénes portan una voz más audible a la hora de definir y fijar las interpretaciones sobre el feminicidio y la violencia de género. A partir de esto, buscamos entrever el espacio al que la mujer queda reducida en este mar de voces en contrapunto. Palabras clave: violencia de género; feminicidio; prensa; voces subalternas

\section{Femicide and gender violence in Argentina press: an analysis of voices, stories and actors}

\begin{abstract}
In this paper we intend to address an analysis of the publication of domestic violence and femicide cases, through a survey conducted with four Argentine newspapers during the first half of 2012. We are interested in enquiring who the privileged representatives by the media are when reporting on the phenomenon, in order to distinguish the space of enunciation that the press gives to diverse actors. Through the analysis of the stories of aggressors, family, justice and victims, we intend to observe the diverse positions and the arguments involved and elucidate who has a louder voice in defining and fixing the interpretations of femicide and gender violence. Based on this, we seek to catch a sight of the reduced space women take up in a sea of voices in counterpoint.
\end{abstract}

Keywords: gender violence; femicide; press; subaltern voices

\section{Feminicídio e violência de gênero na imprensa argentina: análise de vozes, relatos e atores}

\section{Resumo}

No presente trabalho propomo-nos abordar análise acerca da publicação de casos de violência de gênero e feminicídio, mediante um relevamento de quatro jornais argentinos durante o primeiro semestre de 2012. Interessa-nos indagar quais os interlocutores privilegiados pela mídia na hora de informar sobre o fenômeno com o objetivo de poder diferenciar o espaço de enunciação que a imprensa outorga a diversos atores. Mediante análise dos relatos dos agressores, familiares, a justiça e as vítimas, propomos observar as diversas posturas e argumentações colocadas em jogo e dilucidar quem porta uma voz mais audivel na hora de definir e estabelecer as interpretações sobre o feminicídio e a violência de gênero. A partir de isso, visamos entrever o espaço a que a mulher é reduzida neste mar de vozes em contraponto.

Palavras-chave: violência de gênero; feminicídio; prensa; vocês subalternas 


\section{Introducción}

Los debates en torno al feminicidio y la violencia de género han cobrado vigor en la esfera pública, tanto en Argentina como en otros países de América Latina. En el caso argentino, la polémica acerca de la incorporación de leyes sobre feminicidio y violencia contra las mujeres dan testimonio de ello.

A nivel jurídico, diferentes instrumentos en el campo internacional de los derechos humanos -como la Convención para la Eliminación de todas las formas de Discriminación contra la Mujer (CEDAW), y la Convención Interamericana para Prevenir, Sancionar y Erradicar la Violencia contra la Mujer (Convención de Belém do Pará)- avanzaron en contra de la discriminación y la violencia de género en cualquiera de sus manifestaciones, considerándolas como una violación de los derechos humanos de las mujeres.

En los últimos años en Argentina se han sancionado leyes y decretos con el fin de erradicar la violencia y discriminación contra las mujeres. La más significativa data de 2012, cuando se sancionó la Ley 26.791 que incorporó al Código Penal como figura agravante del delito de homicidio simple, el ser cometido por un hombre contra una mujer mediando violencia de género y en los casos en que el homicidio se cometa con el propósito de causar sufrimiento a una persona con la que se mantiene o ha mantenido una relación de pareja o exista un vínculo de consanguinidad ascendente y/o descendente, castigándolo con la máxima pena prevista para nuestro ordenamiento legal.

Algunas de las leyes atañen directamente a los medios de comunicación. Entre las principales podemos nombrar la Ley 26.522 de Servicios de Comunicación Audiovisual que busca promover la difusión de una imagen equilibrada entre hombres y mujeres.

Estas convenciones y fallos no solo tienen un efecto jurídico al punir acciones y hechos de violencia, sino que además adquieren incidencia en las relaciones sociales cotidianas, ya que tienen "el papel de otorgar legitimidad a determinadas posiciones de sujeto mediante su autoridad nominadora [...] actuando como ancla, referente o garante de que el discurso es válido y el sufrimiento social que nomina está oficialmente reconocido" (Segato, 2010, p. 4).

Tanto la lucha contra los diferentes tipos de violencia de género, contra la trata de personas y el feminicidio -así como también por la legalización del aborto-, son disputas por el reconocimiento de 
las mujeres como sujeto de derecho, que tienen como eje los cuerpos femeninos. Son reclamos por el derecho a narrar, de inscribir las demandas colectivas por intereses comunes y de narrarse en el discurso jurídico (Segato, 2011).

Como es de esperarse, esta mayor relevancia pública de la violencia de género y el feminicidio se traduce también en su mayor tematización en los medios de comunicación que devienen canales de gran preeminencia a la hora de visibilizar el fenómeno y de exponer a los diferentes actores que lo rodean en el escenario público.

El modo en que la prensa retrata los casos de violencia de género y feminicidio ha sido un interrogante presente en diversas producciones de la región. Se indaga entonces en los diferentes argumentos, análisis y explicaciones que la prensa pone en juego sobre el fenómeno, focalizando en el modo de retratar las figuras del agresor y la víctima y los estereotipos subyacentes de la mujer, mediante el estudio de la información que se provee de las mujeres en las notas sobre el tema y cómo se las retrata (Ariza Sossa, 2009). Se reflexiona también acerca de la función de los medios de comunicación en la redefinición del papel de la mujer en la sociedad moderna (Cruz Muñoz, 1997) y sobre las representaciones en torno a la violencia contra la mujer en los medios televisivos y consecuente reproducción de prejuicios y estereotipos de género (Vega Montiel, 2010), entre otros numerosos abordajes.

En Argentina, las investigaciones llevadas a cabo por el Observatorio de Sentencias Judiciales y de Medios del Equipo Latinoamericano de Justicia y Género y del Observatorio de Medios, Comunicación y Género perteneciente a la Facultad de Periodismo y Comunicación Social de la Universidad de La Plata, constituyen aportes de gran relevancia al momento de analizar el fenómeno en cuestión. Desde tales espacios, se ha emprendido un seguimiento al tratamiento que los medios de comunicación impresa otorgan a la violencia contra las mujeres, lo cual ha posibilitado el análisis pormenorizado de la frecuencia con que se publican notas sobre la temática, las secciones en las que se lo enmarca, así como el modo en que el fenómeno es retratado (Morelli y Rey, 2011); también se han investigado los estereotipos vigentes en el relato periodístico sobre la violencia de género (Cremona et al., 2013) , así como las diversas estrategias explicativas que la prensa pone en juego a la hora de abordar estos casos, donde se hacen presentes lugares comunes del imaginario social (la obsesión, el crimen pasional, los celos, los desengaños amorosos, entre otros), que tienen por efecto descontextualizar la violencia de género (Pereyra, 2011). 
El presente trabajo se enmarca en las mismas preocupaciones temáticas arriba reseñadas, con la particularidad de que el objetivo consiste en analizar el espacio de enunciación que la prensa otorga a diversos actores en las notas sobre violencia de género y feminicidio. Al considerar a la prensa como un relato que favorece la naturalización de roles y relaciones de género desiguales; como un discurso en el que, en tanto práctica significante, operan condicionamientos ligados a intereses políticos, económicos e ideológicos (Cremona et al., 2013), interrogamos sobre el espacio de enunciación que se le otorga a la mujer en los relatos periodísticos sobre violencia de género y feminicidio: ¿Cuáles son las voces audibles y cuáles las silenciadas en estas narraciones? ¿Tienen las mujeres un espacio de enunciación en la prensa? ¿Cuáles son los interlocutores privilegiados por la prensa a la hora de informar sobre el fenómeno?

Intentaremos responder a estas preguntas por medio del análisis de los relatos de los agresores, los familiares, la justicia y las víctimas. Nos proponemos observar las diversas posturas que adoptan y los relatos que ponen en juego. De esta manera podremos distinguir entre los distintos actores que emergen en la prensa, quiénes portan las voces altas y cuáles las bajas, a la hora de definir y fijar las interpretaciones sobre el feminicidio y la violencia de género.

Por lo tanto, analizamos las narraciones periodísticas a la luz de una perspectiva que presta particular atención a las voces en pugna que yacen en los relatos. Entendemos a la voz como un instrumento de acción y de lucha, una herramienta que permite a los sujetos en posición de subalternidad, dar batalla a las identidades prefijadas que les son señaladas de antemano. Para ello, nos situamos en una intersección entre la perspectiva poscolonial y feminista. Con este fin, nos servimos de los aportes de autores diversos, entre ellos Gayatri Spivak, Ranahit Guha y Jacques Rancière. Además, los análisis pertinentes a la situación de las mujeres serán enriquecidos desde la mirada de autoras feministas latinoamericanas como Rita Segato, Marcela Lagarde, y Karina Bidaseca.

En un primer momento, detallamos la metodología implementada para cumplir con los objetivos propuestos para esta investigación. Luego, analizamos el rol de los medios de comunicación como productores producidos de representaciones sociales y su relación con los estereotipos de género. Seguimos con un recorrido en torno a los conceptos de violencia de género, femicidio, feminicidio y femigenocidio. A continuación nos centramos en los abordajes conceptuales de 
diversos autores, lo que puede denominarse como una teoría de las voces. En el apartado siguiente identificamos las voces de los diferentes actores que emergen en la prensa y las analizamos a la luz de los conceptos descritos en el apartado anterior. El trabajo cierra con algunas consideraciones y reflexiones generales sobre los resultados de este análisis.

\section{Metodologia utilizada y primeras observaciones}

Para esta investigación, realizamos un relevamiento que abarcó el primer semestre del año 2012 sobre noticias de casos de violencia de género y feminicidio en cuatro diarios argentinos: dos nacionales, Clarín y La Nación, y dos provinciales, El tribuno de Salta y La Voz del Interior, de Córdoba. La selección del recorte respondió a distintos factores. Consideramos relevante el análisis de los dos periódicos nacionales en tanto que constituyen los matutinos de mayor antigüedad y masividad en el país. A su vez, nos pareció pertinente la selección de los dos periódicos locales debido a que, según el Observatorio de Femicidios de La Casa del Encuentro "Adriana Marisel Zambrano", después de Buenos Aires, es en las provincias de Córdoba y Salta donde se detectan mayores casos de feminicidios.

Los artículos relevados fueron volcados en una base de datos donde se consignó la fuente, fecha, autor o autora, sección, contenido de la nota, información sobre los actores involucrados y sus declaraciones, la modalidad de agresión (el modo en el que se ejerció la violencia: golpes, incineración, violación, etc.), entre otros. Por un lado, realizamos un análisis cuantitativo de la grilla y luego nos enfocarnos en un análisis cualitativo de la redacción de las notas y las declaraciones que en ellas se relatan.

Durante el período seleccionado relevamos un total de 395 artículos, en su mayoría noticias sobre casos recientemente ocurridos y otros menos numerosos, informes periodísticos sobre violencia de género. Las secciones predilectas donde los periódicos registraron los casos fueron la de policiales o sus secciones análogas en cada uno de los diarios, predominando el tono narrativo propio del estilo policial. De este modo, el 57\% de las noticias fueron encontradas en la sección "Policiales" o "Seguridad", seguido por las secciones "Sociedad/ Ciudadanos" (13\%), "Sucesos/Varios/Información general/opinión" (13\%), "Nacional" (13\%), "Locales" (3\%) y "Política" (1\%). En cuanto a 
los tipos de hecho, se destacan el feminicidio y la violencia de género, representando 40\% y 38\% respectivamente. Los feminicidios impersonales cuentan con una presencia de $12 \%$, la trata de personas $5 \%$ y la desaparición de personas 5\%. Los modos en que los hombres agreden a las mujeres según el contenido de las noticias son principalmente el abuso sexual o violación, la incineración y el apuñalamiento.

A su vez, la cantidad de publicaciones sobre el fenómeno no se detectó estable, sino que varía a través de los meses registrando picos, generalmente a raíz de algún asunto de gran visibilidad mediática. Una de las grandes observaciones que se desprende del relevamiento, es que en los cuatro periódicos seleccionados nos topamos con la mención de los mismos actores: la justicia (los abogados, los jueces, los fiscales), la familia o los amigos de la mujer o del agresor, la policía (peritos, oficiales), los médicos, el agresor y la mujer.

¿Qué sabemos de las mujeres? En muchos casos la información sobre las víctimas se encuentra vedada para proteger su identidad. Pero cuando un caso se torna visible, la información con la que contamos sobre ellas es escasa: el dato más comúnmente nombrado es el tipo de vínculo con el agresor (si eran matrimonio, concubinos, ex pareja, etc.), la cantidad de hijos que tenían e información acerca de la edad y la localidad de residencia. En ningún caso se brinda información sobre clase social ni etnia de la víctima y en pocos casos sabemos sobre su ocupación o profesión.

Con el fin de desentrañar el significado de este modo de retratar el fenómeno, reflexionamos a continuación acerca del carácter de la prensa en nuestras sociedades contemporáneas.

\section{Hacia una aproximación conceptual. La prensa escrita y los estereotipos de género}

Los medios de comunicación constituyen en nuestros dias una de las esferas principales en donde se dirimen los diversos asuntos públicos. Ellos contribuyen a visibilizar u ocultar diferentes escenarios sociales (Morelli y Rey, 2011). Pero los medios no solo informan, sino que también son constructores de representaciones sobre los fenómenos sociales.

Si bien la prensa y los medios de comunicación en general construyen sentido, también son permeados por los significados que 
circulan en la sociedad acerca de los acontecimientos y fenómenos sociales. Como "productor producido" (Sidicaro, 1997), el periódico produce sus propias interpretaciones, al tiempo que es producido al estar sumergido en la sociedad que busca retratar, resultando influido por ella. Es en este juego que se torna posible de un lado, indagar la postura que adopta la prensa detrás de su impronta de imparcialidad y del otro, ciertas representaciones que forman parte de la sociedad en su conjunto.

En tanto productores producidos, los medios impresos hacen eco de las diversas representaciones sociales que rodean a los fenómenos sociales que relatan entre sus páginas. La narrativa mediática sobre los casos de violencia de género y feminicidio constituye un buen ejemplo de esta cuestión. Ciertamente, al analizar el relato del discurso periodístico, salen a la luz los prejuicios y estereotipos que rondan al fenómeno, apelando a los móviles pasionales de locura pasajera que causa el amor, para reconstruir y explicar las posibles causas de tales episodios (Cremona et al., 2013), así como también se encasilla a las mujeres en estereotipos de madre o víctima, y se la interpela como objeto de deseo masculino, mercantilizando el cuerpo, y reduciéndola a un rol reproductivo y doméstico (Del Manzo y Rosales, 2013).

Pero además, la prensa selecciona ciertos eventos y fenómenos de la realidad, los traduce al lenguaje periodístico y los transforma en noticia. Durante este trayecto, escoge ciertos interlocutores, les otorga un espacio de enunciación en sus notas, les brinda legitimidad o los desautoriza. A su vez, hay ciertas voces que no llegan a la prensa y que por ende, permanecen en silencio, desdibujadas detrás de los eventos que se relatan.

Si bien observamos algunos avances en la prensa durante los últimos años sobre los mensajes que brinda sobre esta temática, todavía queda trabajo por realizar para alcanzar un tipo de comunicación no sexista. Como se verá más adelante, una de estas tareas corresponden a la selección de interlocutores válidos para dar testimonio sobre los casos de violencia que aquí nos ocupan.

\section{Violencia de género, femicidio y feminicidio: una aproximación conceptual}

Aquello que se entiende como violencia de género involucra a las agresiones que se ejercen sobre las personas por razones de su género y/o identidad sexual. En este artículo trabajamos específicamente sobre la 
violencia contra las mujeres, considerándola como "cualquier acción o conducta, basada en su género, que cause muerte, daño o sufrimiento físico, sexual o psicológico a la mujer, tanto en el ámbito público como en el privado" (Artículo $1^{\circ}$ de la Convención Belem do Pará, acatada por Argentina en 1996.).

El desenlace más extremo de la violencia de género es el feminicidio. El término en inglés femicide -acuñado por Carol Orlock en 1974 y desarrollado por Diana Russell- hace referencia al asesinato misógino de mujeres a manos de hombres. Marcela Lagarde y de los Ríos (2008) lo han traducido al español como feminicidio, pues considera que el término femicidio es una palabra homóloga a homicidio y alude al asesinato de mujeres; mientras que feminicidio sirve para explicar "al conjunto de violaciones a los derechos humanos de las mujeres que contienen los crimenes y las desapariciones de mujeres [...]. [Los crímenes] tienen en común que las mujeres son usables, prescindibles, maltratables y desechables" (Lagarde y de los Ríos, 2008, p. 216).

El feminicidio se encuentra anclado en la profunda desigualdad estructural entre hombres y mujeres. Según la antropóloga Rita Segato (2003), la dimensión violenta es inherente a la propia dinámica tradicional de género, inseparable de la estructura jerárquica de esa relación, por lo que "erradicar la violencia de género es inseparable de la reforma misma de los afectos constitutivos de las relaciones de género tal como los conocemos y en su aspecto percibido como 'normal" (Segato, 2003, p. 4).

Segato diferencia dos tipos de violencia femicida: por un lado, aquella referida a relaciones interpersonales (violencia doméstica) o a la personalidad del agresor (crimenes seriales) y por el otro, aquella que tiene características no personalizables (Bidaseca, 2011). A este último tipo de violencia la denomina femigenocidio, englobando a los crimenes que

[...] por su cualidad de sistemáticos e impersonales, tienen por objetivo específico la destrucción de las mujeres (y los hombres feminizados) solamente por ser mujeres y sin posibilidad de personalizar o individualizar ni el móvil ni la autoría ni la relación entre perpetrador y víctima. (Segato, 2011, p. 25)

Por lo tanto, hay una diferencia fundamental entre estos crimenes sistemáticos e impersonales y aquellos perpetrados en el ámbito 
doméstico, en el círculo de relaciones cercanas. Mientras que al abrigo del espacio doméstico

[...] el hombre abusa de las mujeres porque puede hacerlo, es decir, porque éstas ya forman parte del territorio que controla, el agresor que se apropia del cuerpo femenino en un espacio abierto, público, lo hace porque debe para mostrar que puede. (Segato, 2004, p. 9)

En la agresión y el abuso, el varón ejerce un poder soberano sobre el cuerpo femenino, la mujer pierde control sobre su espacio-cuerpo, el cual se convierte en un canal de comunicación en dos sentidos: hacia las mujeres, como forma de discipliamiento y hacia los varones, como parte del proceso de producción de masculinidad. De este modo, las marcas sobre el cuerpo que trasluce este tipo de violencia deben ser también considerados en su dimensión expresiva, como simbolo de dominio sobre la voluntad de la mujer: "expresar que se tiene en las manos la voluntad del otro es el telos o finalidad de la violencia expresiva" (Segato, 2004, p. 6).

¿Cómo se retrata este fenómeno tan complejo en la prensa? Tal como se analizará más adelante, no todos los actores sociales involucrados en estos casos portan la misma capacidad para ser oídos.

\section{Sobre voces}

Los canales hegemónicos de enunciación no admiten la presencia de todas las voces por igual. No todos los actores que componen una comunidad cuentan con las mismas condiciones para ser escuchados.

Desde distintas ópticas, ciertos autores han señalado esta dimensión constitutiva de todo orden hegemónico. Uno de ellos es Jacques Rancière (1996), que sostiene que cada orden estatuido se caracteriza por contener una división fundamental: la que se da entre seres parlantes y seres que solo tienen voz. Aquellos que portan la palabra pueden determinar lo justo y lo injusto, lo bueno y lo malo de ese orden. La palabra es inteligible, pero la voz no lo es; la voz solo puede emitir sonidos de agrado o de dolor, de placer o displacer, con lo cual no resulta inteligible al resto de la comunidad: "el orden social se simboliza excluyendo a la mayoría de los seres parlantes a la noche del silencio o del ruido animal de las voces que expresan agrado o sufrimiento" (Rancière, 1996, p. 36). 
Entonces, resulta que ciertos actores se hallan silenciados y además, no pueden ser oídos: ese orden particular no se encuentra preparado para entender lo que estos sujetos tienen para decir. Sus reclamos se interpretan como ruidos, quejas, sonidos incomprensibles. Es por esto que Gayatri Spivak (1985) afirma que el subalterno no puede hablar. Aquellos que son silenciados, cuyas voces se ven condenadas a la ininteligibilidad, se encuentran en una situación de subalternidad. El subalterno no puede hablar puesto que no tiene espacio de enunciación, su discurso no es legítimo frente a ninguna institución. Las voces hegemónicas, altas y sonoras, sofocan a las voces subalternas.

De este modo, las instituciones, los canales legítimos de enunciación, el orden político, entre otros, responden a los preceptos del orden policial, esto es,

[...] un orden de los cuerpos que define las divisiones entre los modos del hacer, los modos del ser y los modos del decir, que hace que tales cuerpos sean asignados por su nombre a tal lugar y a tal tarea; es un orden de lo visible y de lo decible que hace que tal actividad sea visible y que tal otra no lo sea, que tal palabra sea entendida como perteneciente al discurso y tal otra al ruido. (Rancière, 1996, p. 44)

Rancière denomina policía a este orden de cosas vigente, que solo está preparado para escuchar a unos y condenar a otros al mero ruido. Se trata de aquel orden institucional al que se refiere Spivak y que no valida la palabra subalterna.

Ahora bien, ¿de qué manera es posible abandonar la subalternidad? ¿Cómo deshacerse de esta condena al silencio? Rancière y Spivak responden al unísono: la salida es justamente, mediante la posibilidad de habla. La enunciación es la que transforma la posición de subalternidad; la única opción política posible consiste precisamente en dejar de ser subalternos, es decir, intensificar la voz (Bidaseca, 2011). Al igual que Spivak, Rancière afirma que solo mediante la toma de la palabra es posible la desidentificación respecto de las identidades prefijadas por los relatos hegemónicos. Se trata de usurpar los privilegios de la palabra por parte de los que solo tienen voz, es decir, se trata de perturbar el orden policial. Y esta actividad solo puede ser denominada como politica: 
[...] la actividad política es la que desplaza a un cuerpo del lugar que le estaba asignado [...] hace escuchar un discurso allí donde sólo el ruido tenía lugar, hace escuchar como discurso lo que no era escuchado más que como ruido. (Rancière, 1996, p. 45).

Por otro lado, mientras que la vocación para el habla le es negada, el subalterno se encuentra en una posición de gran heterogeneidad. E1 ser subalterno no es una identidad consumada, sino que se trata de una posición de opresión, es una diferencia no homogénea ni generalizable. Muchos y diferentes son los subalternos (Spivak, 1985). Aquellos relegados a la posición de subalternidad se conforman como una multiplicidad de seres anónimos (Rancière, 1996). No obstante, una vez que la voz es intensificada hasta volverse palabra, aquellos que hasta hace poco constituian un mosaico sin forma, atraviesan un proceso de subjetivación: "Toda subjetivación es una desidentificación, el arrancamiento a la naturalidad de un lugar, la apertura de un espacio de sujeto donde cualquiera puede contarse" (Rancière, 1996, p. 53).

De este modo, la toma de la palabra por parte del subalterno es un acto eminentemente político. Una vez que lo hace, instaura un escenario polémico que hace tambalear el orden policial. Pero a su vez, se instituye a él mismo como una identidad, se subjetiva y al hacerlo, abandona su posición de subalterno.

Recapitulando, detrás del orden policial hay sujetos con poca injerencia a la hora de definir las nociones que serán las que imperan. Consideramos que este postulado también involucra a la prensa. En los relatos periodísticos, un puñado de actores va entablando un diálogo en donde pueden detectarse voces altas y voces bajas, según la posibilidad que tienen de disponer del espacio enunciativo. En esta trama, Ranahit Guha (2002/1983) propone realizar una escucha activa de las voces bajas que han sido silenciadas por la voz dominante, es decir, las voces altas. Guha plantea la necesidad de oír las voces que han sido silenciadas a lo largo de la historia. Nuestra intención consiste en evaluar la posibilidad de dicha tarea, considerando la advertencia que hace Spivak al afirmar que no es posible reescribir una historia subalterna a partir de una lectura a contrapelo: según la autora no hay una historia alternativa desde la posición del subalterno, dado que su capacidad para narrar está vedada. 


\section{¿Es posible recuperar la voz de la mujer en el relato periodistico?}

Para observar este juego de voces con matices desiguales, trabajaremos sobre las declaraciones de los diferentes actores, adscribiendo a la metodología propuesta por Bidaseca (2011) que consiste en discernir las voces de los actores: cuándo es la suya propia, cuándo es una voz sofocada, fagocitada, mimetizada o silenciada.

\section{Voces altas $y$ voces bajas en el relato periodistico}

A través de las páginas de los diarios salen a la luz los principales actores que intervienen en este fenómeno y que adoptan posiciones distintas en las que no todos gozan de la misma visibilidad a la hora de intervenir. Comienza a entretejerse un entramado de voces, algunas en tensión, otras en afinidad. Otras voces en cambio, permanecen mudas. En este juego de voces en disputa, la voz mediática subyace al otorgarles espacio de enunciación a determinados actores, con sus respectivas posiciones. En efecto, las voces emergen de un relato mediático particular, que las permea y las atraviesa, tornando complejo dilucidar la frontera entre el actor de carne y hueso y su construcción mediática. Como un actor latente, desde las sombras, la prensa adjetiva, enfatiza, desautoriza o soslaya ciertas voces. A continuación, daremos cuenta de este tejido complejo de voces y su tesitura particular.

\section{La voz del agresor: entre la negación y el arrepentimiento}

El agresor, generalmente pareja o ex pareja de la víctima, figura con cierta frecuencia en las notas. El hombre tiene la oportunidad de relatar su versión de los hechos en la prensa y deviene interesante la persistencia de cierto testimonio en este actor. En efecto, en las numerosas ocasiones que el hombre da cuenta de lo ocurrido durante el acto de violencia, adopta una postura que puede señalarse con claridad: la de la negación del suceso y la exculpación de su responsabilidad sobre el crimen. Quizás el caso más conocido sea el de Eduardo Vázque $z^{10}$ que incineró a su mujer, Wanda Taddei, en el 2010: "Nunca le pegué a mi mujer, nunca le falté el respeto. Era una relación de amor genuino [...]Yo no la rocié con alcohol ni la prendí fuego" (La Nación, 2012, febrero 28).

${ }^{10} \mathrm{El}$ nombre de los protagonistas proviene de fuentes públicas (artículos de prensa). 
Otro tipo de repertorio puesto en acción por estos actores es el del repentino olvido de lo acontecido. Un ejemplo paradigmático de ello es el de Marcelo Tomaselli que tras asesinar a su pareja, Carla Figueroa, a puñaladas, afirmó haber olvidado lo ocurrido:

Lo único que recuerdo es que agarré la cuchilla, nada más [...] Soy culpable, pero del hecho no recuerdo nada. Sólo que desperté en una celda [...] Me declaro culpable, aunque no recuerdo lo que hice. (Clarín, 2012, junio 28; La Nación, 2012, junio 18; El Tribuno, 2012, junio 19);

Esto pese a que tiempo atrás supo afirmar que "La volveria a matar. Yo sufrí mucho, pero ya está" (El Tribuno, 2012, abril 9; La Nación, 2012, abril 10).

Asimismo, tal ejercicio de quitarse o invalidar la responsabilidad que se tiene sobre los hechos entraña su contrapartida: el depositar la culpa en las mujeres. Es así como, de acuerdo a esta versión de los hechos en palabras del fiscal de la causa, son las mujeres las que se infligen el daño como resultado de su voluntad o de un torpe accidente:

Según declaró el muchacho, poco después al ingresar, él la vio que tomaba un encendedor y se prendía fuego, ante lo cual le da unas palmadas para apagarle el fuego. Cuando ve que no puede controlar las llamas, sale al frente de la casa donde vive su mamá. (Clarín, 2012, junio 20).

Finalmente, otro de los argumentos esgrimidos por el hombre es el arrepentimiento. Una vez más, quienes mejor ejemplifican esta postura son Eduardo Vázquez:

Muchas veces pienso si pude haber hecho algo más para salvarla [...] Perdí a mi mujer, a mi mejor amiga y al amor de mi vida, y hasta proyectos futuros que tenía con ella [...] perdí mi libertad y mi hogar [...] (Clarin, 2012; El Tribuno, 2012, junio 14)

y Marcelo Tomaselli:

Pido perdón y no le deseo a nadie que esté viviendo lo que estoy viviendo yo [...] Mátenme, no quiero vivir más [...] Soy culpable, me 
hago cargo de que todo el mundo ya sabe, solo quiero que me condenen por algo que hice. (Clarín, 2012, junio 20; La Nación, 2012, junio 18).

\section{La voz de la justicia: entre la absolución y la demonización del agresor}

El sistema judicial es sin duda, uno de los interlocutores que goza de mayor legitimidad a la hora de zanjar sobre los hechos válidos que hacen al fenómeno. Cumple por un lado, un rol informativo al especificar la situación en que ocurrió el suceso y los datos relevantes que rodean al mismo. Desde los agentes policiales hasta los jueces, estos actores figuran describiendo la escena del crimen, los actores involucrados, los hechos ocurridos, la instancia en la cual se encuentra la investigación, entre otros datos. Pero además de informar, estos actores adoptan ciertas posiciones.

En virtud de la posición del agresor antes caracterizada, la justicia se encuentra constreñida a corroborar el carácter de accidente, suicidio o asesinato de la mujer. Es así como una de las posturas que suelen adoptar los representantes del sistema judicial consiste en corroborar o desmentir las declaraciones prestadas por el hombre. En este sentido, nos topamos con la constante duda de la justicia en torno a la naturaleza de lo ocurrido y sucede con cierta frecuencia que en esta tarea la versión del hombre logra salir airosa: "para la fiscalía no hay testigos del hecho ni declaraciones que lo señalen a Cortez como autor de la agresión" (Clarín, 2012, marzo 18); "el fiscal busca establecer si la mujer fue víctima de un accidente, de un ataque o si ella misma se lesionó" (Clarín, 2012, junio 20; El Tribuno, 2012, junio 17). No obstante, en ciertas ocasiones la justicia cruza este umbral de la duda y dictamina ciertos hechos como resultado de una emoción violenta o de un arrebato pasional:

La Justicia cree que actuó bajo emoción violenta [...] Para los jueces, el hombre fue influenciado por las revelaciones que ella le hizo sobre un amante [...] lo dejó libre, tras analizar las pericias psiquiátricas que aseguraban que hubo "emoción violenta" y "arrebato pasional". (Clarín, 2012, junio 9). 
Por supuesto que también en numerosas ocasiones, la justicia declara culpable al acusado dictaminando las penas correspondientes. Sin embargo, llama la atención cómo tal postura se exacerba en algunos de estos casos. La condena de Marcelo Tomaselli1 ${ }^{11}$ ilustra con claridad esta postura. En las notas reveladas sobre el caso, la declaración de la Cámara del Crimen de General Pico evidencia el tono de reprobación por parte de la justicia:

No cabe la más mínima duda de que el estímulo emotivo que produjo la reacción criminal de Tomaselli nació pura y exclusivamente de su mente $[. .$.$] anidaba la idea [...] albergaba un sentimiento$ de muerte en su espíritu [...] Para la Justicia, mató con satisfacción. (Clarin, 2012; La Nación, 2012, junio 28)

De esta manera, se produce una suerte de péndulo en la postura de la justicia que oscila entre la absolución del agresor y su demonización.

\section{Las voces de los familiares de las victimas: un intento de revertir veredictos}

Si las voces del hombre y la justicia revelan cierta indeterminación sobre la naturaleza de los hechos, son los familiares quienes intervienen con más contundencia y certeza a la hora de dirimir acerca de lo ocurrido. Expresan dolor, desconsuelo y sobre todo denuncia. Se hacen presentes reclamando justicia, intentando revertir las interpretaciones en aquellos casos donde la versión de suicidio o accidente cobran vigor. En estas ocasiones, las voces familiares entran en tensión con las judiciales y con la voz del agresor, como puede verse en la declaración de la madre de la víctima Carolina Rueda, y luego en voz de las hermanas de Paula González, en un intento de revertir la hipótesis de que su muerte por incineración había sido un suicidio:

A mi hija la asesinaron y la dejaron abandonada. No fue un accidente de tránsito porque tenía cortes y otras lesiones. (El Tribuno, 2012, mayo 18); "Estaba muy contenta con su embarazo. Tenía

${ }^{11}$ Luego de pasar ocho meses en prisión por violar a su novia Carla Figueroa, fue liberado gracias a la figura del avenimiento (solicitado por la joven). Poco tiempo después la asesinó, hecho a partir del cual la figura del avenimiento se discutió en el Congreso de la Nación argentino y perdió vigencia; Tomaselli fue condenado a prisión perpetua. 
ganas de vivir [...] Paula tiene otros tres hijos a los que ama y nunca se quitaría la vida de esa manera. (Clarín, 2012, junio 20)

Estas declaraciones de los familiares también manifiestan las falencias en los mecanismos estatales para prevenir este tipo de violencia, como puede observarse en la afirmación del padre de Romina Palomino, asesinada por su novio mediante incineración: "Yo pienso que se podría haber evitado si alguien nos escuchaba" (La Nación, 2012, marzo 27).

Por momentos, ante la virtual ausencia de la voz de la mujer, las voces familiares narran aspectos que rodeaba a la pareja y que los otros actores omiten en su discurso. De este modo, señalan los antecedentes de violencia que habian sufrido las mujeres, como puede leerse en esta declaración de la hermana de una mujer incinerada:

De lunes a viernes eso era de mil maravillas; viernes a la noche, sábado y domingo era un descontrol, como que no compatibilizaban [...] él le pegaba [...] [en un episodio anterior, el ahora detenido] quiso cortarle la garganta con un cuchillo. (Clarín, 2012, junio 20).

En otras oportunidades, estas voces dejan entrever la ira contra el agresor, como vemos en el comentario del hermano de Carla Figueroa: "Lo quería matar. Sólo espero que se pudra en la cárcel porque lo odio con toda mi alma" (La Nación, 2012, junio 28; Clarín, 2012, junio 28).

\section{La voz (imperceptible) de la mujer}

Rescatar la voz de la mujer se torna una tarea ardua en las notas estudiadas. En principio, dado que la prensa relata casos de violencia extrema, muchos de los cuales culminan con la mujer hospitalizada en estado grave o en el peor de los casos, con su muerte, su voz resulta inevitablemente sofocada. Permanece imperceptible y solapada bajo otras voces a veces parafraseadas por otros actores, sin lograr hablarle directamente a la prensa.

En los escasos momentos en que las mujeres pueden hablar, narran las agresiones que padecieron: 
Cuando llegó, me mandó a la cocina mientras me golpeaba, no sé por qué. Hasta que agarró un frasco de alcohol y me roció. Yo le rogué que no me quemara [...] No me gusta verme así, con todo mi cuerpo arruinado. (Clarín, 2012, enero 8)

También encontramos los casos opuestos, es decir declaraciones (algo contradictorias) de mujeres que defienden a sus agresores, como en el caso de Verónica Schneider:

Tuvimos discusiones como todo matrimonio, pero sólo una vez me pegó, me dejó el ojo negro y lo denuncié, pero nada más [...] Todo lo que se dijo de él es falso. No es violento para nada. Siempre me dio todo y aparte lo amo. (Clarín, 2012, abril 15)

Cuando hablan mujeres que fueron víctimas de la explotación sexual, se percibe en sus palabras testimonios de impunidad:

Es peor denunciar que no denunciar. Acá no hay nadie que te pueda proteger de nada y las autoridades están entongadas con los narcotraficantes. Es increíble cómo todos los días mueren chicas. Yo estoy viva de milagro. (La Nación, 2012, mayo 1).

De todas formas, muchas veces la autenticidad de los relatos de las mujeres es puesta en duda por el cronista del diario con comentarios como "supuesta víctima" o "supuesta mujer violada", apoyándose para esto en la voz de la justicia, la cual no puede determinar a priori la culpabilidad de los hombres. En este sentido, resulta interesante la postura que adopta la mujer en la prensa cuando es parafraseada por otros, como se dilucida en las palabras escuchadas por el agresor y los vecinos, de parte de Elsa Cano, acuchillada por su marido:

"Perdí 13 años de mi vida con vos, no pienso volver acá [...] Callate che, boludo "gorreado"12 Siempre fingí con vos, me vuelvo con Juan [su ex pareja]. Él es un hombre de verdad y siempre me hizo gozar. A él siempre lo seguí amando. Con él me saco las ganas. (Clarin, 2012, junio 9)

${ }^{12}$ En Córdoba, Argentina, se refiere al hombre cuya mujer le ha sido infiel. 
En este caso, la imagen de mujer provocadora e infiel pareceria ser el justificativo de la violencia.

Pero algunas voces de mujeres comienzan a hacerse oír; denuncian la falta de políticas y acciones de la justicia para protegerlas, Laura Elías afirma: "La violencia primero fue psicológica y después física. Creo que la Justicia debería haber dicho algo al respecto" (La Nación, 2012, junio 4). También se pronuncian para alentar a otras mujeres a salir de la violencia, como Carolina Morales: "Las mujeres no tenemos que callar nunca más. Ante situaciones como la mía hay que ser consciente de la vida. Yo expuse la mía y estas son las consecuencias" (Clarin, 2012, enero 8).

Estas expresiones buscan el efecto de salir de la situación de subalternidad, empiezan a quebrar la hegemonía masculina y surgen en los intersticios, en las grietas. Estas mujeres se yerguen y obtienen un espacio de enunciación. ¿Por qué entre tantas notas, encontramos solo dos testimonios? Las palabras de Laura además son ejemplo de lo que les ha costado hacer oír su voz: el Estado no las escuchó. Correrse de lugar de subalternas les ha costado prácticamente la vida. Como pudimos observar, a través de las páginas de los periódicos van saliendo a la luz actores diversos. Ellos hablan, protestan, imploran, dictaminan o bien, callan. A su vez, comienzan a trazarse ciertas afinidades entre algunas de estas voces, que se refuerzan entre sí, logrando robustecer ciertas interpretaciones sobre los hechos. De este modo, a la negación del hombre con respecto al acto de violencia, le sigue la vacilación de la justicia sobre lo acontecido.

En este contexto, la voz de la mujer se encuentra desdibujada, parafraseada por el discurso de otros actores. En ciertas oportunidades, serán los familiares los encargados de ser sus portavoces. No obstante, los familiares ocupan el lugar de la queja y la denuncia, pero con escasa injerencia a la hora de dictaminar el curso de las interpretaciones. Hablan desde el lugar del damnificado, se trata de una voz dañada, una voz que habla por lo bajo. La familia puede hablar, pero en las noticias periodísticas su lugar de enunciación parece encarnar un mero condimento de dramatismo.

Como contrapartida, la voz de la justicia representa la verdad. Y la del agresor, a veces avalada -otras veces denostada y demonizada-, es una voz fuerte y audible, de algún modo más inteligible a la hora de asignar representaciones (en la prensa) sobre los acontecimientos. En este mar de voces, la voz de la mujer se encuentra colonizada por la de 
los otros actores y la prensa. Los hombres vuelven a tener relevancia en el ámbito público y las mujeres quedan ocultas en el privado.

No debemos olvidar que estas voces son recuperadas por el discurso mediático. En efecto, más allá de lo que estas voces proclamen, es la prensa la que les otorga espacio de enunciación y los señala como interlocutores válidos para relatar los episodios de violencia hacia la mujer. La voz mediática proporciona espacio, acentúa rasgos, subraya legitimidades, de modo tal que responde a los lineamientos policiales -aquellos que hacen prevalecer la palabra masculina y que escuchan la palabra de la mujer como un quejido incomprensible. Gracias a su carácter de productores producidos, este modo de representar el fenómeno no deja de hacer eco de una serie de prejuicios y estereotipos presentes en la sociedad. De este modo, en los relatos que la prensa recoge de los diversos casos, se refuerzan ciertos prejuicios del imaginario social, prejuicios propios del marco interpretativo policial, tal como el del arrebato pasional para fundamentar los actos violentos hacia las mujeres, o de la mujer desviada, provocadora o infiel y por tanto merecedora de la violencia que le ocasionó la muerte. En todos estos casos se omite el carácter social del fenómeno.

En este trabajo se observa que la persistencia de estas interpretaciones asociadas a estereotipos y prejuicios sociales más vastos, se corresponden con la virtual ausencia de la voz de las mujeres. La mujer, entre sombras, permanece ajena a los casos que a ella conciernen y de los que ha sido protagonista. Tal invisibilización termina por despersonalizarla y anonimizarla en los relatos mediáticos (Cremona et al., 2013); se convierte en una muerta más, otra víctima de la violencia, un número que engrosa las filas de una vasta lista de casos que la prensa representa como idénticos. Como un sujeto subalternizado, la mujer yace en los relatos mediáticos como una masa sin forma.

\section{Comentarios finales. Lo que las voces no dicen (o lo que la prensa desoye): ¿Puede la mujer hablar en la prensa escrita?}

Como se ha demostrado, resulta dificil rescatar la voz de las mujeres víctimas de violencia en la prensa. Cuando esto se hace posible, su mensaje se encuentra deformado, parafraseado o bien, no es lo suficientemente estridente para acallar las voces altas de los otros actores que gozan de mayor legitimidad. En los artículos trabajados, la voz femenina obra como ruido, incapaz de determinar lo justo y lo injusto 
o de erigir una interpretación sobre lo ocurrido. Por su parte, la voz de la justicia y del hombre perpetrador de la violencia parecen tener mayor capacidad para hacerse entender, son voces altas, claras, inteligibles y competentes a la hora de orientar las interpretaciones sobre lo ocurrido.

Los medios de comunicación son voces hegemónicas que sofocan las voces de las mujeres, en este caso, víctimas de la violencia ejercida por los hombres. De este modo, estas mujeres no pueden hablar porque carecen de espacio de enunciación y no porque sean mudas (Bidaseca, 2011). En términos de Spivak, la mujer estaría en una posición subalterna en los relatos de la prensa. Y no solo no son escuchadas cuando aún poseen voz, sino que una vez asesinadas, tampoco se repara en los cuerpos que hablan a través de sus marcas al poner en duda la violencia ejercida por el hombre.

El camino para abandonar la subalternidad es tomar la palabra y hacerla propia. Alzar la voz, tornarla palabra, hacerla inteligible; tareas todas que conllevan una salida del anonimato que implica la subalternidad, un camino hacia la subjetivación, la conformación como sujeto con una identidad atribuida por sí mismo, un camino que solamente puede ser político. En el colectivo de mujeres, esta tarea cuenta con larga data. Las mujeres han sabido defenderse y organizarse, han salido a hablar al espacio público. Son las voces de las militantes de organizaciones de mujeres y feministas. Solo resta que los medios amplíen el espectro de interlocutores cuando de lo que se trata es de zanjar sobre la situación de violencia en la que se encuentran sumergidas algunas de ellas.

\section{Referencias}

Ariza Sossa, G. R. (2009). Representaciones sociales de la violencia en las relaciones de pareja en la prensa de Medellin en el Siglo XXI", El Colombiano 2001 - 2008. La Chiva 2002 - 2008. Revista Venezolana de Estudios de la Mujer, 14 (32), 71-97.

Bidaseca, K. (2011). Mujeres blancas buscando salvar a mujeres color café: desigualdad, colonialismo jurídico y feminismo postcolonial. Revista Andamios, 8 (17), 61-89.

Bidaseca, K. y Vázquez Laba, V. (Comps.). (2011). Feminismos y poscolonialidad. Descolonizando el feminismo desde y en América latina. Buenos Aires: Editorial Godot. 
Clarín. (2012, enero 1 a junio 30).

Cremona, M. F., Rosales, M. B. y Actis, M. F. (2013). Las representaciones del cuerpo femenino en el discurso mediático: La experiencia del Observatorio de Medios, Comunicación y Género. X Jornadas de Sociología, Universidad de Buenos Aires, Ciudad de Buenos Aires, Argentina.

Cruz Muñoz, A. (1997). Mujer y medios de comunicación en Centroamérica. Anuario de Estudios Centroamericanos, 23(1-2), 35-48.

Del Manzo, M. B. y Rosales, M. B. (2013). Comunicación y género: el cuerpo femenino en el tratamiento mediático del aborto. En Anzorena, C. y Zurbriggen, R. (Comps.). El aborto como derecho de las mujeres. Otra historia es posible (pp. 195-208), Buenos Aires: Editorial Herramienta.

El Tribuno de Salta. (2012, enero 1 a junio 30).

Guha, R. (2002/1983). Las voces de la historia y otros estudios subalternos. Barcelona: Editorial Critica.

La Casa del Encuentro. (s.f.) ONG. Disponible en: http:/ / www.lacasadelencuentro. org/portada.html

Lagarde y de los Ríos, M. (1996) Género y Feminismo. Desarrollo Humano y Democracia. Madrid: Editorial Cuadernos inacabados.

Lagarde y de los Ríos, M. (2008). Antropología, feminismo y política: violencia feminicida y derechos humanos de las mujeres. En Bullen, M. y Diez Mintegui, C. (Coords.) Retos teóricos y nuevas prácticas (pp. 209-239). España: Editores AnkulegiAntropologiaElkartea.

La Nación. (2012, enero 1 a junio 30).

La Voz del Interior. (2012, enero 1 a junio 30).

Morelli, M. y Rey, P. (2011). La violencia hacia las mujeres en los medios de comunicación. Hallazgos del Observatorio de Medios-2010. En Equipo Latinoamericano de Justicia y Género (ELA). Los derechos de las mujeres en la mira (pp 19-43.). Buenos Aires: Informe Anual de los Observatorios de Sentencias Judiciales y de Medios.

Pereyra, M. R. (2011). Pensar la violencia de género. Estrategias explicativas en los discursos periodísticos. En Equipo Latinoamericano de Justicia y Género (ELA). Los derechos de las mujeres en la mira (pp. 79-101). Buenos Aires: Informe Anual de los Observatorios de Sentencias Judiciales y de Medios.

Rancière, J. (1996). El desacuerdo. Política y filosofia. Buenos Aires: Nueva Visión

Segato, R. (2003). Las estructuras elementales de la violencia: contrato y status en la etiología de la violencia. Brasilia: Série Antropología.

Segato, R. (2004). Territorio, soberanía y crimenes de segundo estado: la escritura en el cuerpo de las mujeres asesinadas en Ciudad Juárez. Brasilia: Serie Antropología. 
Segato, R (2010) Femi-geno-cidio como crimen en el fuero internacional de los Derechos Humanos: el derecho a nombrar el sufrimiento en el derecho". De próxima aparición en Fregoso, R. L. y Bejarano, C. Una cartografia del feminicidio en las Américas 2010. México, DF: UNAM-CIIECH.

Segato, R. (2011, mayo 4-5). Femigenocidio y feminicidio: una propuesta de tipificación. Mesa "Feminismos Poscoloniales y descoloniales: otras epistemologías". II Encuentro Mesoamericano de Estudios de Género y Feminismos, Guatemala.

Sidicaro, R. (1997). Consideraciones a propósito del diario La Nación. En Wainerman, C. y Sautu, R. (Eds.). La trastienda de la investigación (pp. 73-90). Buenos Aires: Editorial Belgrano.

Spivak, G. (1985). ¿Puede el subalterno hablar? (Amícola J. Trad.). Revista OrbisTertius, 6 (6), 175-235.

Vega Montiel, A. (2010). La responsabilidad de la televisión mexicana en la erradicación de la violencia de género contra las mujeres y las niñas: apuntes de una investigación diagnóstica. Comunicación y Sociedad, (13), 43-68.

\section{Cómo citar este artículo}

Angélico, R., Dikenstein, V., Fischberg, S. y Maffeo, F. (2014). El feminicidio y la violencia de género en la prensa argentina: un análisis de voces, relatos y actores. Universitas Humanística, 78, 281-303. http://dx.doi.org/10.11144/ Javeriana.UH78.fvgp 